\title{
REDUCTION OF THE VIBRATION IN A HELICOPTER BLADE USING PIEZOELECTRIC ACTUATORS
}

\section{S. Gluhihs, A. Kovalovs}

Institute of Materials and Structures of Riga Technical University. Azenes St. 16-323, LV-1048, Riga, Latvia. E-mail: s_gluhih@inbox.lv;kovalovs@bf.rtu.lv Received 0301 2005, accepted 09062006

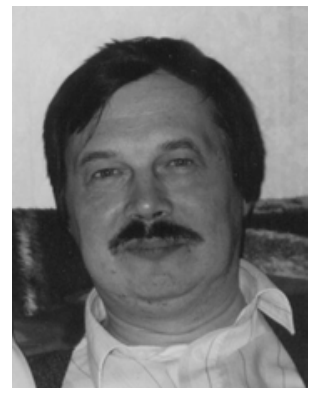

Sergejs GLUHIHS, Ph. D, Associate Professor.

Date and place of birth: March 11, 1953, Riga.

Education: 1976 - St. Petersburg Technical University, Ph. D. degree in mechanical engineering.

Experience: 1976 - Present - Institute of Materials and Structures of Riga Technical University.

Publications: Author of numerous (more than 40) journals and conferences papers in strength of rubbery and composite materials.

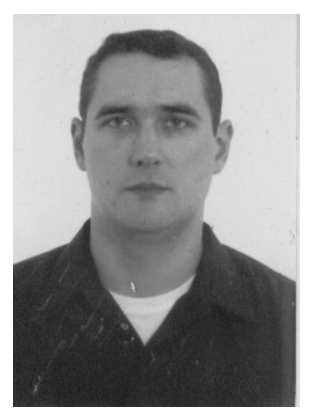

Andrejs KOVALOVS, Ph. D student

Date of birth: April 11, 1975.

Education: 1996 - Bachelor's degree in mechanical engineering, Riga Aviation University; 1997 - Engineer's degree in mechanical engineering, Riga Aviation University; 1999 - Master's degree in mechanical engineering, Riga Aviation University.

Experience: 2001 - present - PhD student, Institute of materials and structures, Riga Technical University Publications: Co-author of three scientific articles.

\begin{abstract}
A method to reduce vibration in a helicopter blade under a variable harmonic pressure loading using piezoelectric actuators is presented. The model of a helicopter blade is an equivalent aluminum plate. To decrease the amplitude in the resonant frequency range, piezoelectric actuators are set on the top of the plate. The results were obtained by using the ANSYS finite element code. The temperature analogy method instead of a variable pressure load is assumed for numerical analysis. The influence of piezoelectric actuators on the plate is considered. It is shown that the use of piezoelectric actuators to decrease the vibration of the plate is highly efficient. The most rational arrangements of piezoelectric actuators and the required amount of electric voltage are determined.
\end{abstract}

Keywords: ANSYS, piezoelectric, plate, vibration, thermal analogy.

\section{Introduction}

Methods of vibration control are of importance in various fields of application such as aerospace, civil, and mechanical engineering.

This new structural concept requires the use of sensors and actuators for controlling the mechanical behavior of structural systems when using the converse piezoelectric effect to induce control forces and moments. During the past few years, piezoelectric materials have been extensively used as actuators and sensors for noise and vibration control. Piezoelectric materials exhibit both direct and converse piezoelectric effects. The direct effect (electric field generation as a response to mechanical strains) is used in piezoelectric sensors; the converse effect (mechanical strain is produced as a result of an electric field) is used in piezoelectric actuators.

The two commonly used types of piezoelectric materials are PZT (Lead Zirconate Titanate) piezoceramics and PVDF polymer films. Piezoelectric materials can be used in smart structures as sensors and/or actuators in applications such as shape control, active damping, and acoustic noise suppression [6]. 
The use of smart materials and active control technology for helicopter vibratory load reduction has been investigated by several researchers [3-5, 8, 9]. Two principal strategies have been investigated for reducing rotor dynamic loads. The first is the trailing edge flaps actuated with piezobimorphs and piezoelectric actuators $[1,2]$. The second is the controllable twist blades with embedded piezoceramics $[8,9]$.

The object of this study is investigating a helicopter blade with surface-bonded actuators under loading. The helicopter blade is modeled as an aluminum plate. An analysis shows that the form of tensional modes determines the optimum placement of actuators.

Due to the increasing interest in the design of complex structures with piezoelectric actuators and the need for fast and simple implementation of piezoelectric control systems, major FEM code developers have incorporated or provided the tools for creating piezoelectric elements.

To incorporate the voltage effects into the model, a simple thermal analogy was used.

The influence of piezoelectric actuators on a plate was investigated. It was found that the use of piezoelectric actuators for decreasing the vibration of the plate is highly efficient. The most rational arrangements of piezoelectric actuators and the required amount of electric voltage were determined.

\section{Modeling approaches}

ANSYS is a finite-element analysis package widely used in industry for simulating the response of a physical system to structural loading and thermal and electromagnetic effects. ANSYS employs the finiteelement method to solve the underlying governing equations and the associated problem-specific boundary conditions.

The ANSYS mechanical finite element program offers two- and three-dimensional piezoelectric coupledfield elements for modeling structures with piezoelectric actuators/sensors. The program involves static, modal, full harmonic, and transient analyses.

For decreasing the number of finite elements, we used a SHELL99 element, which is suitable for layered applications of a structural shell model.

To incorporate the voltage effects into the ANSYS model, a simple thermal analogy was used.

The piezoelectric coefficients characterizing the actuator are introduced as thermal expansion coefficients.

The piezoelectric charge constant $d_{3 I}$ divided by the PZT ceramic thickness $t_{p z t}$ is an equivalent coefficient of thermal expansion $[7,10]$,

$$
\alpha=\frac{d_{31}}{t_{p z t}} .
$$

The voltage $V$ is equivalent to the temperature difference $\Delta T$ :

$$
V \sim \Delta T
$$

\section{Structural model}

An aluminum plate with one clamped edge is examined. Two piezoelectric actuators are bonded to the plate, which has the following geometrical parameters: length $L=4.0 \mathrm{~m}$, width $B=0.2 \mathrm{~m}$, and thickness $t=$ $0.025 \mathrm{~m}$ (Fig 1).

The mechanical properties of the aluminum plate are as follows: $E=70 \mathrm{GPa}, \nu=0.28$, and $\rho=2700 \mathrm{~kg} / \mathrm{m}^{3}$.

The dimensions of the PZT-4 piezoceramics are length $l=0.4 \mathrm{~m}$, width $b=0.1 \mathrm{~m}$, and thickness $t_{p z t}=$ $0.001 \mathrm{~m}$.

The mechanical properties of PZT- 4 are $E_{x}=E_{y}=$ $78.6 \mathrm{GPa}, E_{z}=62.5 \mathrm{Gpa}, G_{x z}=G_{y z}=26 \mathrm{GPa}, G_{x y}=30$ $\mathrm{GPa}, v_{y z}=v_{\mathrm{xz}}=0.36, v_{x y}=0.29$, and $\rho=7500 \mathrm{~kg} / \mathrm{m}^{3}$.

Here, $E$ is Young's modulus; $G$ is shear modulus, $v$ is Poisson ratio, and $\rho$ is density.

The piezoelectric charge constant is $d_{31}=-1.183 \mathrm{e}-$ $10 \mathrm{~m} / \mathrm{V}$.

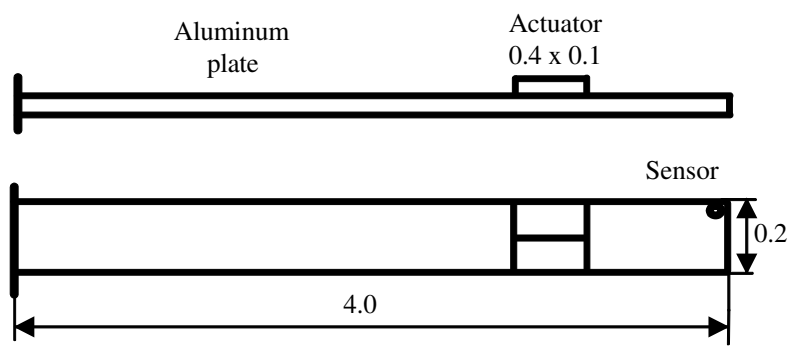

Fig 1. Aluminum plate with piezoelectric actuators

A multilayered SHELL99 element is used to describe the rotor blade finite construction, where the first layer represents an aluminum plate and the second layer represents PZT actuators.

The plane pressure load is $q=q_{0} \cdot \sin (\omega t)$, where $q_{0}=1 \mathrm{~Pa}$. This load is considered for the twisting vibration analysis of the plate. The plane pressure creates the twisting moment. The constant damping ratio is 0.01 .

\section{Numerical Results and Discussion}

The behavior of the aluminum plate with the top surface bonded to piezoelectric actuators is studied in detail. The plate parameters are studied by varying the location of the piezoelectric actuators. The plate is discredited using 10 equal coupling areas. The length of each piezoelectric actuator is the same as that of one area.

For example, two pairs of piezoelectric actuators are bonded on position 3 (Fig 2).

\subsection{Modal analysis}

Figure 3 shows the results for the first four twist mode shapes with corresponding frequencies $f$ of 48.0, 141.6, 237.0, and $338.4 \mathrm{~Hz}$. 


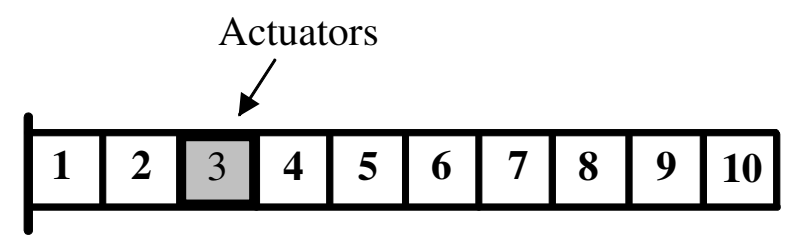

Fig 2. Illustration of an aluminum plate with PZT pairs for position 3

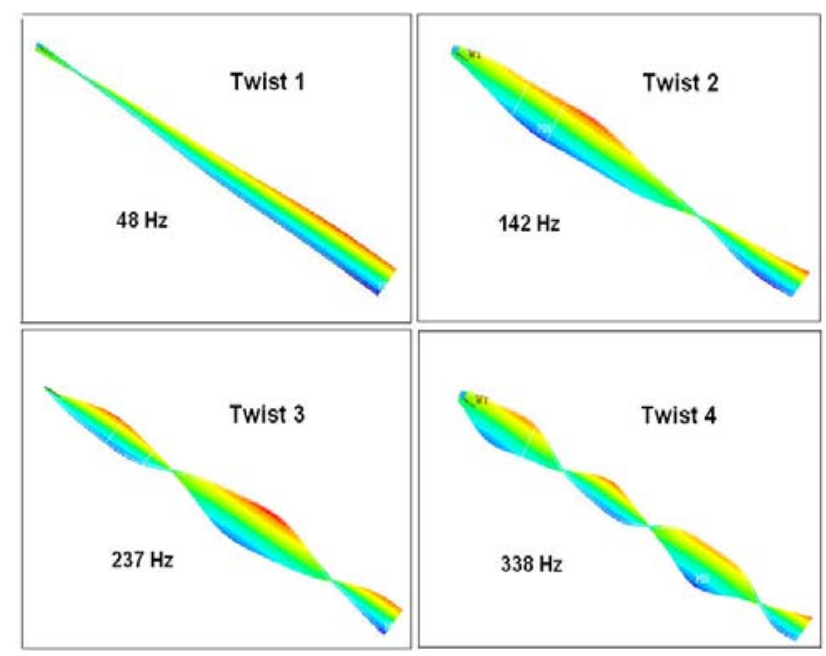

Fig 3. Twist mode shapes of an aluminum plate with piezoelectric actuators

\subsection{Harmonic analysis}

The actuators are activated in series with the application of an electric field to every pair of piezoelectric actuators. The electric field may have an inphase or out-of-phase voltage acting on the actuators. As seen from table 1, due to the thermal load (voltage) applied to the pair of piezoelectric actuators, the amplitude decreases.

The decrease in vibration is the characterizing function of reduction. The reduction $\mathrm{R}$ is given by

$$
R=\left(1-\frac{A}{A_{0}}\right) \cdot 100 \%
$$

where $\mathrm{A}$ is the amplitude with $\mathrm{V} \neq 0$ and $\mathrm{A}_{0}$ is the amplitude with $\mathrm{V}=0$.

For position $\mathrm{N} 3$, one may see that when voltage is $700 \mathrm{~V}$ the maximum reduction is equal to $96.2 \%$ (Tab 1, and Fig 2).

Also, for each frequency of the twist mode shape and for each position, the maximal reduction and the optimal voltage were found. The optimal voltage, maximal reduction, and relative Reduction/Optimal Voltage for the first four twist mode shapes is shown in tables 2-4.

As seen from table 4 , the optimal positions of actuators correspond to the maximal ratio reduction/optimal voltage for each of the twist mode shapes. For example, the best position for the second twist is number 4.
Table 1. Optimal voltage, reduction, and amplitude for the first twist mode shape

\begin{tabular}{|c|c|c|}
\hline Position 3 & \multicolumn{2}{|c|}{$f=\mathbf{4 8 . 0}$ Hz } \\
\hline $\begin{array}{c}\text { Voltage } \\
\text { V }\end{array}$ & $\begin{array}{c}\text { amplitude A } \\
\text { (m) }\end{array}$ & $\begin{array}{c}\text { reduction R } \\
\text { (\%) }\end{array}$ \\
\hline 0 & $1.65 \mathrm{E}-05$ & 0.0 \\
\hline 100 & $1.41 \mathrm{E}-05$ & 14.5 \\
\hline 200 & $1.20 \mathrm{E}-05$ & 27.3 \\
\hline 500 & $4.40 \mathrm{E}-06$ & 73.3 \\
\hline $\mathbf{7 0 0}$ & $\mathbf{6 . 2 5 E}-07$ & $\mathbf{9 6 . 2}$ \\
\hline 800 & $2.45 \mathrm{E}-06$ & 85.2 \\
\hline 1000 & $7.60 \mathrm{E}-06$ & 53.9 \\
\hline
\end{tabular}

Table 2. Maximal reduction for the first four twist mode shapes

\begin{tabular}{|c|c|c|c|c|}
\hline \multirow{2}{*}{ Position } & \multicolumn{4}{|c|}{ Maximal reduction (\%) } \\
\cline { 2 - 5 } & twist 1 & twist 2 & twist 3 & twist 4 \\
\hline 1 & 85.2 & 62.3 & 45.5 & 63.0 \\
\hline 2 & 93.3 & 91.7 & 91.7 & 85.0 \\
\hline 3 & 96.2 & 91.9 & 91.6 & 90.2 \\
\hline 4 & 97.2 & 92.5 & 83.7 & 85.4 \\
\hline 5 & 96.0 & 91.6 & 93.9 & 89.0 \\
\hline 6 & 96.8 & 91.8 & 90.8 & 89.9 \\
\hline 7 & 92.9 & 64.1 & 90.0 & 76.0 \\
\hline 8 & 97.9 & 83.5 & 77.4 & 85.0 \\
\hline 9 & 93.7 & 87.5 & 83.7 & 16.4 \\
\hline 10 & 95.3 & 90.1 & 90.4 & 77.9 \\
\hline
\end{tabular}

Table 3. Optimal voltage for the first four twist mode shapes

\begin{tabular}{|c|c|c|c|c|}
\hline \multirow{2}{*}{ Position } & \multicolumn{4}{|c|}{ Optimal Voltage, V } \\
\cline { 2 - 5 } & twist 1 & twist 2 & twist 3 & twist 4 \\
\hline 1 & -70 & -15 & -4.0 & -3.0 \\
\hline 2 & 1200 & 15 & 2.5 & 0.8 \\
\hline 3 & 700 & 11 & 2.3 & 2.0 \\
\hline 4 & 500 & 10 & 5.5 & -1.5 \\
\hline 5 & 400 & 11 & -6.0 & -1.0 \\
\hline 6 & 350 & 20 & -3.0 & -4.0 \\
\hline 7 & 300 & 80 & -2.5 & 1.0 \\
\hline 8 & 300 & -25 & -6.0 & 0.8 \\
\hline 9 & 300 & -15 & 5.0 & 3.5 \\
\hline 10 & 300 & -13 & 3.0 & -1.3 \\
\hline
\end{tabular}

Next, the effect of the geometric dimensions on the control of plates was studied. Figure 4 shows schematic diagrams for the first four twist mode shapes. As seen from table 5, the optimal voltage decreases with an increase in the number of bonded piezoelectric actuators for all four twists. A good result of the reduction is also illustrated in table 6 for each twist mode shape. 
Table 4. Ratio Reduction/Optimal Voltage for the first fourtwist mode shapes

\begin{tabular}{|c|c|c|c|c|}
\hline \multirow{2}{*}{ Position } & \multicolumn{4}{|c|}{ Reduction/Optimal Voltage } \\
\cline { 2 - 5 } & twist 1 & twist 2 & twist 3 & twist 4 \\
\hline 1 & -1.217 & -4.15 & -11.4 & -21.0 \\
\hline 2 & 0.078 & 6.11 & 36.7 & 113.3 \\
\hline 3 & 0.137 & 8.35 & 40.7 & 45.1 \\
\hline 4 & 0.194 & 9.25 & 15.2 & -56.9 \\
\hline 5 & 0.240 & 8.33 & -15.7 & -89.0 \\
\hline 6 & 0.277 & 4.59 & -30.8 & -22.5 \\
\hline 7 & 0.310 & 0.80 & -36.0 & 76.0 \\
\hline 8 & 0.326 & -3.34 & -12.9 & 113.3 \\
\hline 9 & 0.312 & -5.83 & 16.7 & 4.7 \\
\hline 10 & 0.318 & -6.93 & 30.1 & -62.3 \\
\hline
\end{tabular}

Table 5. Optimal Voltage

\begin{tabular}{|c|c|c|c|c|}
\hline $\begin{array}{c}\text { Dimension } \\
(\%)\end{array}$ & \multicolumn{4}{|c|}{ Optimal Voltage (V) } \\
\cline { 2 - 5 } & $\begin{array}{c}\text { twist } \\
1\end{array}$ & twist 2 & twist & twist \\
& 300 & 15.00 & 6.00 & 1.50 \\
\hline 10 & 150 & 6.50 & 2.00 & 0.65 \\
\hline 20 & 100 & 4.00 & 1.35 & 0.60 \\
\hline 30 & 75 & 2.75 & 1.15 & \\
\hline 40 & 65 & 2.25 & & \\
\hline 50 & 55 & 2.25 & & \\
\hline 60 & & & & \\
\hline
\end{tabular}

Table 6. Reduction

\begin{tabular}{|c|c|c|c|c|}
\hline $\begin{array}{c}\text { Dimension, } \\
(\%)\end{array}$ & \multicolumn{4}{|c|}{ Reduction (\%) } \\
\cline { 2 - 5 } & twist & twist & twist & twist \\
& 1 & 2 & 3 & 4 \\
\hline 10 & 95.3 & 91.7 & 94.0 & 85.4 \\
\hline 20 & 97.8 & 90.5 & 97.0 & 90.2 \\
\hline 30 & 96.1 & 89.7 & 94.0 & 91.4 \\
\hline 40 & 94.3 & 91.2 & 91.3 & \\
\hline 50 & 97.5 & 91.1 & & \\
\hline 60 & 95.7 & 92.6 & & \\
\hline
\end{tabular}

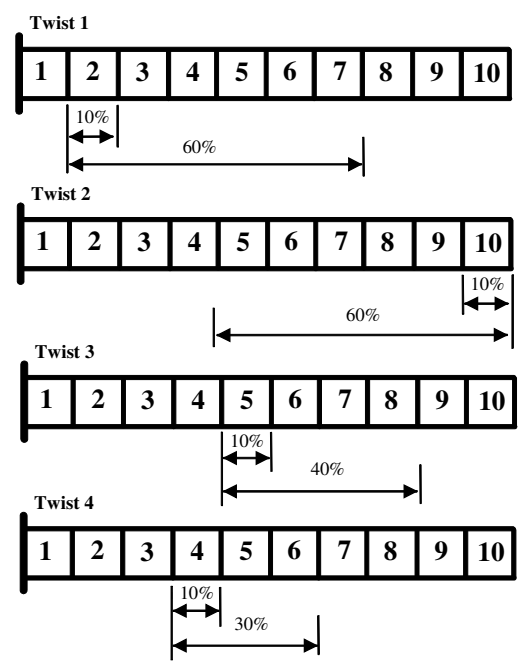

Fig 4. Schematic diagrams of the cases studied

\section{Conclusions}

The reduction of vibration in an aluminum plate under variable harmonic pressure loading with surfacebonded piezoelectric actuators was studied numerically by using the commercially available ANSYS packages. A thermal load according to the thermal analogy modeled the applied voltage.

Thus, we may conclude the following:

- By using this method, it is found that the form of torsion modes determines the optimum placement of actuators.

- It is also found that the length of piezoelectric actuators affects the active control of plates.

\section{References}

1. Ben-Zeev O., Chopra I. Advanced in the development of an intelligent helicopter rotor employing smart trailing edge flaps // SPIE North American Conf. on Smart Structures and Materials (February 27-March 3, 1995). - 1995.

2. Centolanza1 L.R., Smith E.C., Munsky B. Induced-shear piezoelectric actuators for rotor blade trailing edge flap // Smart Mater. Struct. 2002. - Vol. 11. - P. 24-35.

3. Chattopadhyay A., Liu Q., Nam C. Rotor vibratory response analysis using smart materials and aero elastic control / AIAA-99-1504.

4. Chattopadhyay A., Liu Q., Gu H. Aeromechanical modelling of smart composite rotor blade for vibration reduction // 53rd Annual Forum of the American Helicopter Society (Washington DC, May 29-31, 1998). - 1998.

5. Chopra I. Development of a smart rotor // 19th Eur.Rotorcraft Forum (Cernobbio, Italy, September 14-16, 1993). - 1993. - Paper No 6.

6. Giurgiutiu V., Rogers C.A. Review of SmartMaterials Actuation Solutions for Aero elastic and Vibration Control // Journal of Intelligent Material Systems and Structures.

7. Horner G., Taleghami B. Single Axis Piezoceramic Gimbal // Journal of Intelligent Material Systems and Structures. 2001. - Vol 12, Issue 03.

8. Park C. Chopra I. Modeling piezoceramic actuation of beams in torsion $/ / 35^{\text {th }}$ Structures, Structural Dynamics and Materials Conf. and Adaptive Structures Forum, (Hilton Head, NC, April 18-21, 1994). - 1994.

9. Spangler R. L. Jr., Hall S.R. Piezoelectric actuators for helicopter rotor control / AIAA-901076.

10. Taleghani B. Validation of high displacement piezoelectric actuator finite element models // Proceedings of SPIE - The International Society for Optical Engineering, Society of Photo Optical Instrumentation Engineers. - Bellingham, USA, 2000. - Vol 4073. - P. 37-45. 